\title{
PERPADUAN WISATA SEJARAH DENGAN WISATA AIR DI KAWASAN BENTENG VASTENBURG SURAKARTA
}

\author{
Ismadi \\ Program Studi Arsitektur, Fakultas Teknik, Universitas Tunas Pembangunan Surakarta \\ ismadi.ir@gmail.com
}

\author{
Abito Bamban Yuuwono \\ Program Studi Arsitektur, Fakultas Teknik, Universitas Tunas Pembangunan Surakarta \\ bamban.yuuwono@gmail.com
}

\begin{abstract}
Abstrak
Selama ini obyek wisata sejarah Benteng Vastenburg Surakarta tidak banyak dikunjungi wisatawan, sementara di sekitar lokasi merupakan obyek wisata modern berupa wisata kuliner dan wisata belanja semakin banyak didatangi pengunjung setiap harinya. Meskipun letaknya berdampingan, secara fungsional kegiatan kedua jenis obyek wisata ini tampak terpisah dan berjalan sendiri-sendiri tanpa ada interaksi apapun. Hal ini sangat tidak menguntungkan bagi keduanya. Perlu dicarikan solusi untuk mensinergikan potensi kedua obyek wisata tersebut agar lebih menguntungkan bagi kedua belah pihak, bagi pemerintah daerah khususnya, dan bagi seluruh masyarakat pada umumnya. Permasalahannya adalah bagaimana memadukan antara obyek wisata sejarah dengan obyek wisata modern secara fungsional sehingga terjalin hubungan yang saling mendukung dan saling menguntungkan? Tujuan penelitian ialah untuk mendapatkan bentuk perpaduan obyek wisata sejarah dengan obyek wisata modern di kawasan Benteng Vastenburg Surakarta. Metoda penelitian menggunakan analisis kualitatif yang eksploratif dari data-data primer yang diambil melalui survey langsung ke lapangan, dan data sekunder dari dokumen-dokumen tentang Benteng Vastenburg. Hasil penelitian menemukan bentuk pemaduan yang paling tepat untuk kondisi kawasan wisata Benteng Vastenburg adalah pengembangan fungsi parit benteng dan lahan sekitarnya untuk obyek wisata air.
\end{abstract}

Kata kunci: Perpaduan, wisata sejarah, wisata air

\begin{abstract}
So far, historical tourism objects of Vastenburg Fortress Surakarta are not visited by many tourists, while around the location are modern tourist objects in the form of culinary tours and shopping tours that are increasingly visited by visitors every day. Even though they are located side by side, functionally the activities of these two types of tourism objects appear separate and run independently without any interaction. This is very unfavorable for both of them. It is necessary to find a solution to synergize the potential of the two tourism objects so that it is more profitable for both parties, for the local government in particular, and for the whole community in general. The problem is how to combine historical tourism objects with modern tourism objects functionally so that mutually supportive and mutually beneficial relationships are established. The aim of this research is to find a combination of historical tourism objects with modern tourism objects in the area of Vastenburg Fort, Surakarta. The research method used is an exploratory qualitative analysis of primary data taken through direct field surveys, and secondary data from documents about Vastenburg Fort. The results of the study found that the most appropriate form of integration for the conditions of the Vastenburg Fort tourist area was the development of the function of the fort's moat and the surrounding land for water tourism objects.
\end{abstract}

Keywords: combination, historical tourism, water tourism 


\section{PENDAHULUAN}

\section{A. Latar Belakang}

Benteng Vastenburg Surakarta merupakan salah satu benteng peninggalan kolonial belanda di Indonesia. Benteng Vastenburg dibangun tahun 1745 oleh Gubernur Jendral Baron Van Imhoff. Benteng ini dibangun untuk kepentingan pertahanan (pusat Garnisun) pemerintahan belanda dan sebagai titik pengawasan belanda terhadap penguasa Surakarta, khususnya penguasa Keraton Surakarta. Lokasi benteng ini bersebrangan dengan tempat kediaman gubernur Belanda (sekarang dipakai sebagai kantor walikota Surakarta) yang dipisah oleh jalan Jendral Sudirman (jalan protokol kota Surakarta). Kawasan di sekitar jalan Jendral Sudirman Surakarta ini sekarang terkenal dengan sebutan kawasan Gladak. Ada 3 tempat yang mempunyai keterkaitan sejarah di kawasan ini, yakti Keraton Surakarta, Benteng Vastenberg, dan Tempat tinggal Gubernur Jendral Baron Van Imhoff (Balai Kota). Jadi kawasan Gladak merupakan kawasan yang sangat bersejarah bagi kota Surakarta. Nilai sejarah ini harus dipertahankan dan dipelihara dengan sebaikbaiknya.

Seiring berjalannya waktu, kawasan disekitar Benteng Vastenburg saat ini telah berkembang pesat menjadi pusat perdagangan, pusat perkantoran, pusat rekreasi kuliner dan pusat rekreasi perbelanjaan. Begitu pesatnya perkembangan rekreasi moderen di sekitar Benteng Vastenburg menyebabkan pamor Benteng sebagai obyek wisata sejarah jadi tenggelam, masyarakat jadi kurang tertarik. Masyarakat lebih tertarik untuk menikmati wisata yang modern.

Selama ini obyek wisata sejarah Benteng Vastenburg Surakarta tidak banyak dikunjungi wisatawan, sementara di sekitar lokasi merupakan obyek wisata modern berupa wisata kuliner dan wisata belanja semakin banyak didatangi pengunjung setiap harinya. Meskipun letaknya berdampingan, secara fungsional kegiatan kedua jenis obyek wisata ini tampak terpisah dan berjalan sendiri-sendiri tanpa ada interaksi apapun. Hal ini sangat tidak menguntungkan bagi keduanya. Perlu dicarikan solusi untuk mensinergikan potensi kedua obyek wisata tersebut agar lebih menguntungkan bagi pemerintah dan masyarakat kota Surakarta khususnya dan masyarakat seluruh Indonesia pada umumnya.

\section{B. Permasalahan}

Bagaimana memadukan antara obyek wisata sejarah dengan obyek wisata modern (wisata kuliner dan wisata belanja) secara fungsional sehingga terjalin hubungan yang saling mendukung dan saling menguntungkan? Permaduan fungsional diartikan sebagai adanya satu obyek yang bisa difungsikan sebagai obyek wisata sejarah tapi juga bisa difungsikan sebagai obyek wisata modern.

\section{METODE PENELITIAN}

Penelitian ini menggunakan metode analisis kualitatif yang eksploratif. Data-data primer didapat dari survey langsung di lapangan dan 
data sekunder didapat dari dokumen-dokumen tentang Benteng Vastenburg. Data lain didapat dari buku-buku pustaka, artikel di jurnal ilmiah, majalah, media cetak \& elektronik. Berikut arah penggunaan data dalam analisis:

\section{A. Data Lokasi}

Lokasi penelitian terletak di kawasan Gladak, kelurahan Kedung Lumbu, kecamatan Pasar Kliwon , kota madya Surakarta (Gambar $1)$.

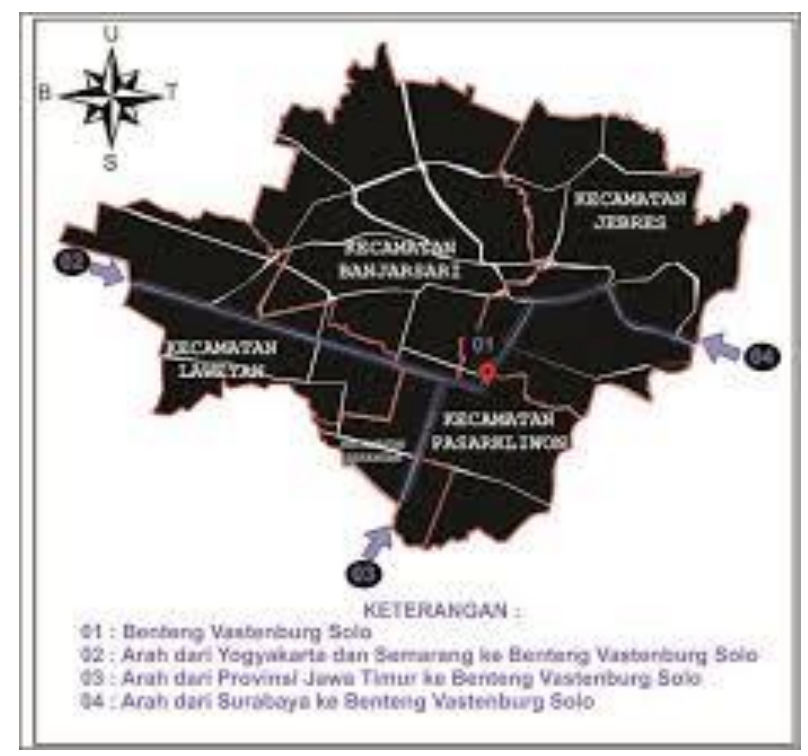

Gambar 1. Lokasi Penelitian

\section{B. Data tata guna tanah}

Dipakai untuk mengetahui hubungan fungsional antara Benteng Vastenburg dengan bangunan-bangunan yang ada disekelilingnya. Merupakan data sekunder yang didapat dari dinas tata kota Surakarta dan dari internet.

\section{Data kondisi existing site}

Dipakai untuk mengetahui permasalahan nyata yang ada dilapangan. Merupakan data primer yang didapat dari pengamatan dan pengukuran langsung.

\section{Data sejarah.}

Dipakai untuk mengetahui latar belakang sejarah dan budaya setempat yang berpengaruh pada penyelesaian masalah. Data ini didapat dari buku pustaka dan jurnal.

\section{HASIL DAN PEMBAHASAN}

\section{A. Analisis Kawasan}

Ada beberapa hal yang perlu dicermati dan dijadikan bahan analisis dalam proses perencanaan pemaduan obyek wisata sejarah dan obyek wisata modern di kawasan Benteng Vastenburg ini, yaitu:

\section{Kondisi Tata Guna Lahan di Sekitar Benteng Vastenburg}

Kondisi tata guna lahan saat ini di selatan benteng adalah obyek wisata kuliner yang terkenal dengan nama "Galabo" singkatan dari “Gladag Langen Bogan” yang berarti makanan idaman Gladag. Wisata kuliner ini sangat ramai dikunjungi masyarakat baik siang hari maupun malam hari (Gambar 6). 


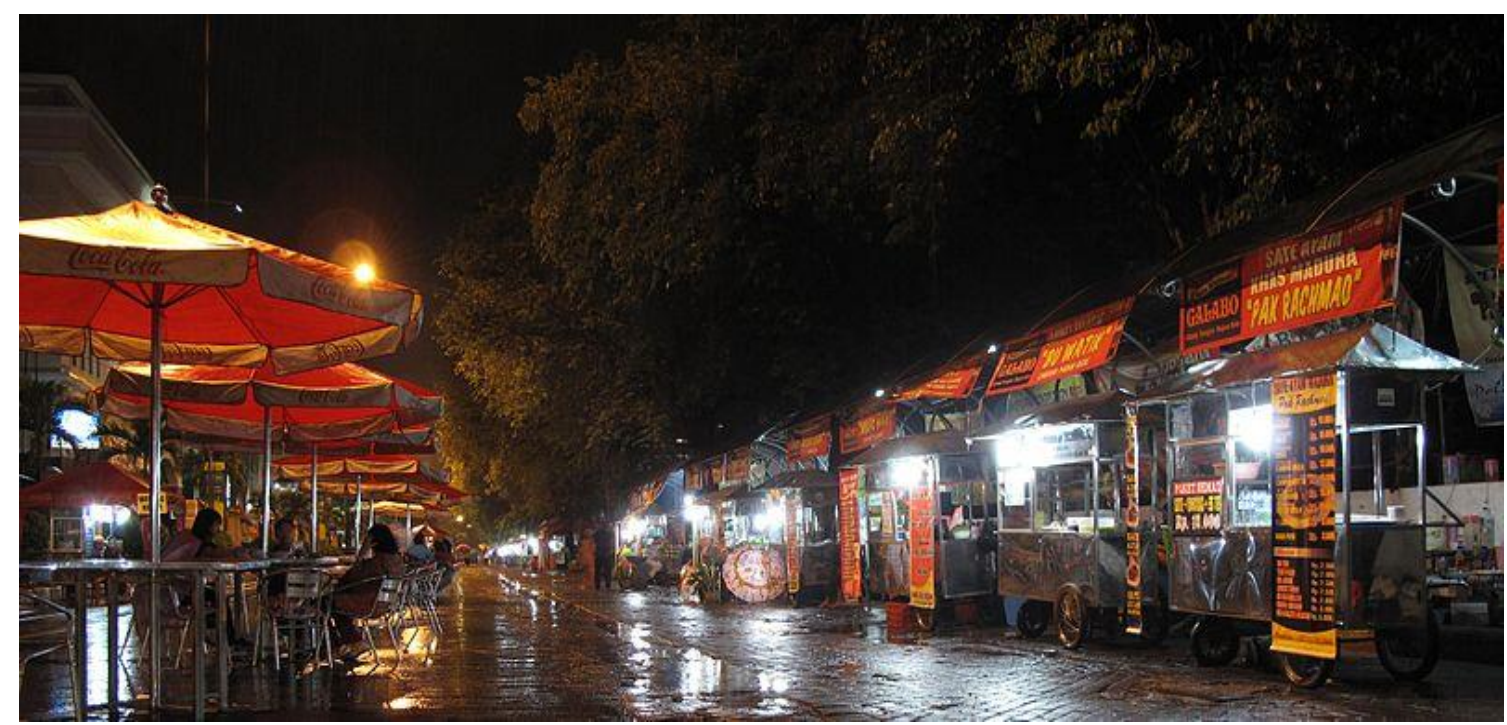

Gambar 6. Kawasan Wisata Kuliner Galabo Surakarta di malam hari

Lokasi pusat kuliner Galabo ini tepatnya berada di sepanjang jalan Mayor Sunaryo Surakarta yang juga merupakan jalur wisata kereta SoloWonogiri.

Di selatan pusat kuliner Galabo adalah Pusat Perbelanjaan fashion, kain, dan batik yang juga merupakan pusat wisata belanja di kota Surakarta. Pusat perbelanjaan ini banyak dikunjungi pula oleh pedagang-pedagang dari luar kota yang ingin berbelanja secara grosir dan sekaligus menjadi salah satu tujuan wisata mereka. Kawasan Galabo dan pusat wisata belanja ini dilewati jalur kereta wisata solowonogiri (Gambar 7) sehingga semakin menambah keramaian aktifitas wisata di tempat ini.
Kawasan selatan Benteng merupakan lokasi yang unik karena letaknya sebagi pusat wisata moderen kota Surakarta berdampingan langsung dengan pusat wisata sejarah Benteng Vastenburg. Saat ini kedua jenis obyek wisata ini berjalan sendiri-sendiri.

Di sebelah barat Benteng Vastenburg merupakan pusat perkantoran, termasuk kantor walikota Surakarta yang merupakan bekas lokasi kantor gubernur belanda, sehingga termasuk juga kwasan bersejarah (Gambar-8).

Bentuk bangunan kolonial semakin memperkuat nuansa sejarah. Hal ini terlihat pada gedung Bank Indonesia (BI), Kantor Pos, dan Bank Danamon.

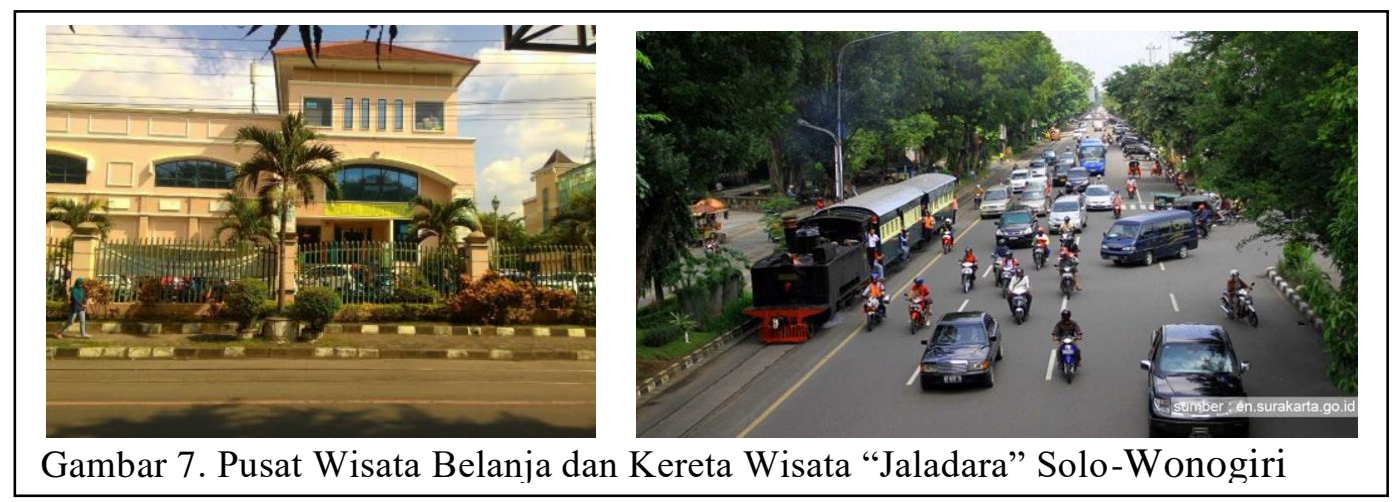




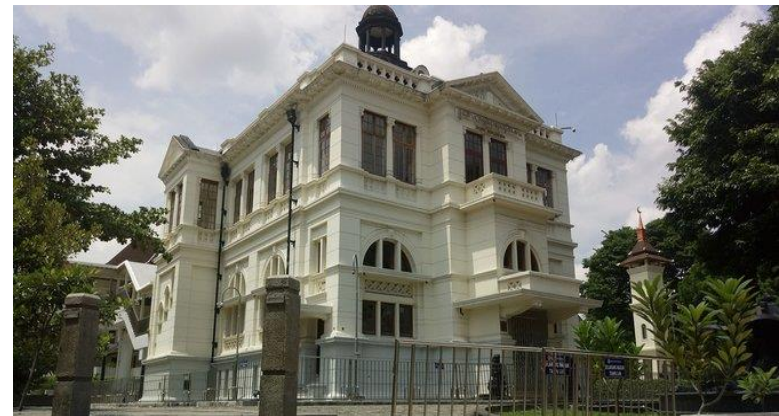

- Gedung Bank Indonesia

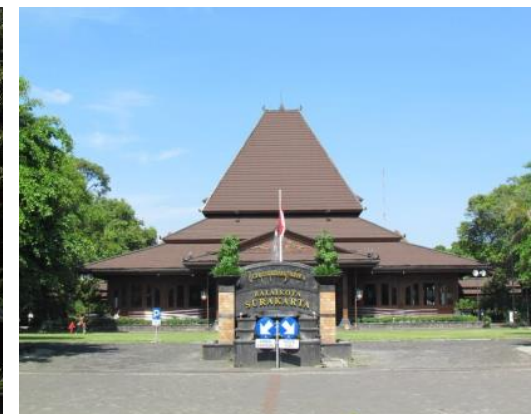

- Gedung Balaikota Surakarta

Gambar 8. Gedung Perkantoran yang berada di sebelah barat Benteng

Bahkan saat ini jalan Jendral Sudirman yang menghubungkan antara kawasan Benteng Vastenburg dengan kawasan Perkantoran telah dirubah perkerasan aspalnya menjadi paving menyambung paving jalan masuk kawasan benteng sehingga lebih memberi kesan menyatu sebagai satu kawasan bersejarah yang berkaitan. Di sebelah utara merupakan kawasan perkantoran, sungai Pepe, dan pasar tradisional yang bersejarah pula.

Pasar tradisional "Pasar Gede" merupakan kawasan pecinan yang bentuk bangunannya bernuansa kolonial (Gambar 9).

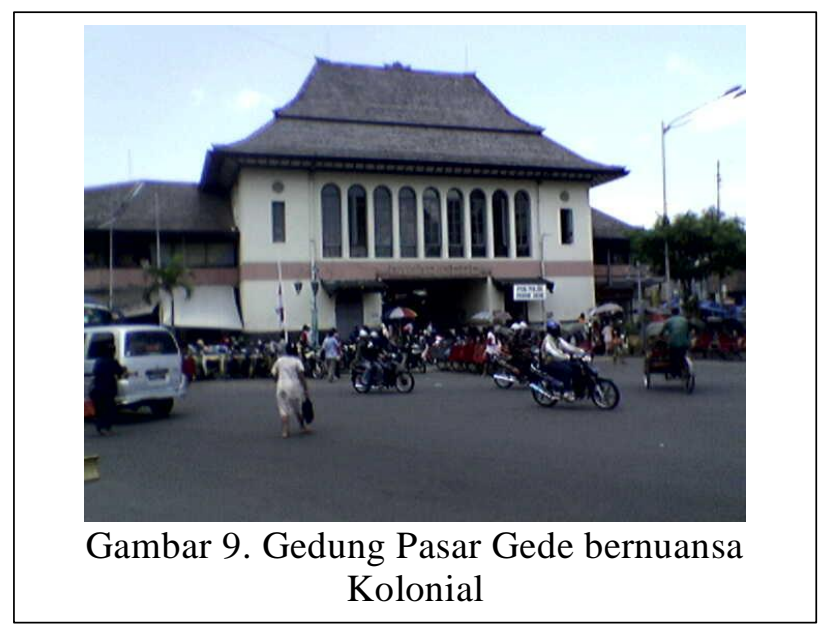

Pasar Gede juga merupakan pusat wisata jajanan pasar tradisional yang banyak dikunjungi oleh para turis mancanegara maupun domestik. Pasar gede yang dibangun oleh belanda mempunyai keterkaitan nilai sejarah dengan balaikota dan benteng Vastenburg yakni sebagai fasilitas perdagangan di masa itu.

\section{Obyek Wisata yang Terpisah}

Dari data-data yang telah didapatkan, terlihat bahwa secara fisik antara obyek wisata Benteng Vastenburg dengan obyek wisata modern sekelilingnya tidak ada akses yang menghubungkan. Kedua komplek wisata ini terpisah oleh pagar pembatas dan satu gedung perkantoran bank. Akses masuknya sendirisendiri dan terletak di titik lokasi yang berjauhan. Disamping itu tidak ada satupun fasilitas bersama yang digunakan oleh kedua obyek ini, misalnya ruang parkir, toilet umum, ataupun tempat ibadah. Hal ini menyebabkan masing-masing obyek terisolasi satu dengan lainnya (Gambar-10)

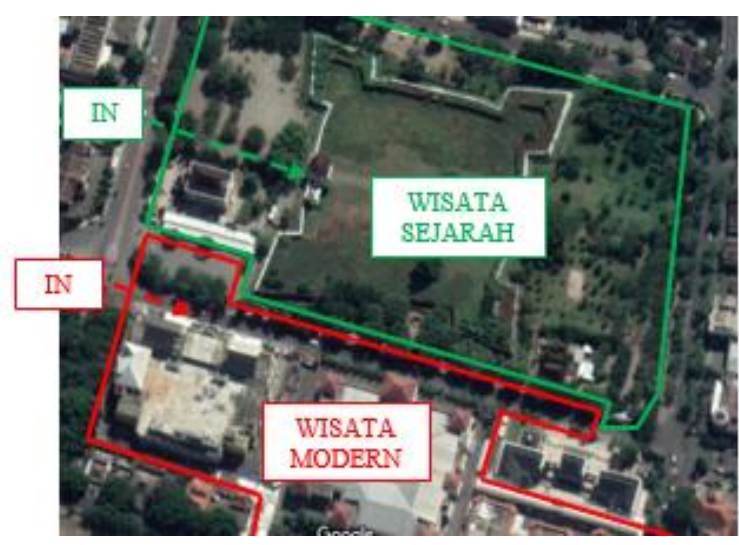

Gambar-10. Dua Komplek Wisata Terpisah 


\section{B. Perpaduan Fungsional Obyek Wisata} Sejarah dengan Obyek Wisata Moderen

Melihat eratnya kaitan nilai sejarah antara kawasan Benteng Vastenburg dengan kawasan sekelilingnya, dan juga eratnya kaitan fungsional sebagi tujuan wisata, maka sangat potensial kawasan ini dikembangkan menjadi satu kawasan wisata kota yang terpadu dan sinergis. Terpadu karena lokasinya menyatu, sehingga perencanaan tata ruangnya bisa merupakan satu kesatuan perencanaan (demikian juga perencanaan jenis-jenis obyek wisatanya), dan sinergis karena keduanya bisa dijalin hubungan yang saling menguntungkan.

Setelah mengamati dan menganalisis tata ruang dan fungsi-fungsi ruang yang ada di kedua komplek wisata tersebut, maka satu kemungkinan yang paling tepat dilakukan untuk mensinergikan kedua obyek wisata tersebut adalah mengembangkan fungsi Parit Benteng dan lahan disekitarnya menjadi satu obyek wisata yang dapat diakses dari kedua komplek wisata tersebut.

Parit merupakan bagian terluar dari bangunan Benteng sehingga paling memungkinkan untuk difungsikan sebagai penghubung dengan kawasan diluar benteng.

Untuk melengkapi obyek wisata parit ini perlu dibuatkan sarana rekreasi air lain dan fasilitas umum bersama (Taman parkir, Toilet, Tempat Ibadah) di lahan yang dapat diakses dari kedua arah komplek wisata tersebut, seperti kolam renang anak, kolam keceh, kolam luncur, dan kolam kesehatan.

\section{Pengembangan Fungsi Parit}

Ada beberapa hal penting yang perlu ditinjau terlebih dahulu mengenai bangunan parit benteng ini sebelum melakukan pengembangan fungsinya. Hal-hal penting tersebut adalah:

\section{a. Nilai Sejarah Parit Benteng Vastenburg}

Bangunan parit Benteng Vastenburg merupakan bagian tak terpisahkan dari bangunan Benteng secara keseluruhan. Secara keseluruhan bangunan Benteng vastenburg terdiri dari Tembok Benteng, Parit, Jembatan Jungkit, Barak, dan Lapangan rumput. Tembok Benteng dengan tinggi $6 \mathrm{~m}$ mempunyai denah berbentuk bujur sangkar seluas $31.000 \mathrm{~m}^{2}$ dengan penonjolan ruang (bastion) di ke empat sudutnya. Parit dibangun mengelilingi tembok benteng (Gambar.3). Lebar parit $3 \mathrm{~m}$ dengan kedalaman $2 \mathrm{~m}$. Dahulu parit dipergunakan untuk pertahanan Benteng dari serangan musuh. 


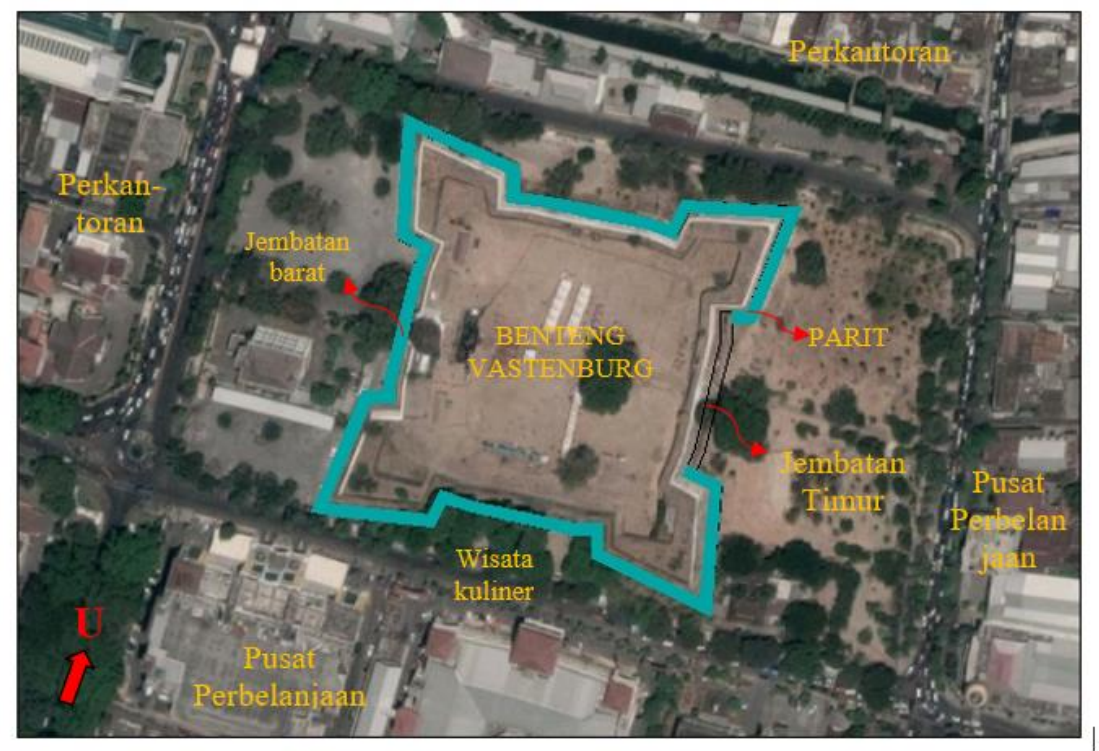

Gambar-3. Komplek Benteng Vastenburg Surakarta

Dengan adanya parit yang mengelilingi tembok menyebrangi parit. Jembatan ini dulu aslinya benteng, maka akses masuk kedalam benteng berbentuk jungkit dan sewaktu-waktu bisa hanya bisa melalui 2 pintu gerbang yaitu pintu diangkat-turunkan, tapi sekarang sudah gerbang barat dan pintu gerbang timur. Di berubah menjadi jembatan permanen dari beton depan pintu gerbang ada jembatan untuk (Gambar 4).

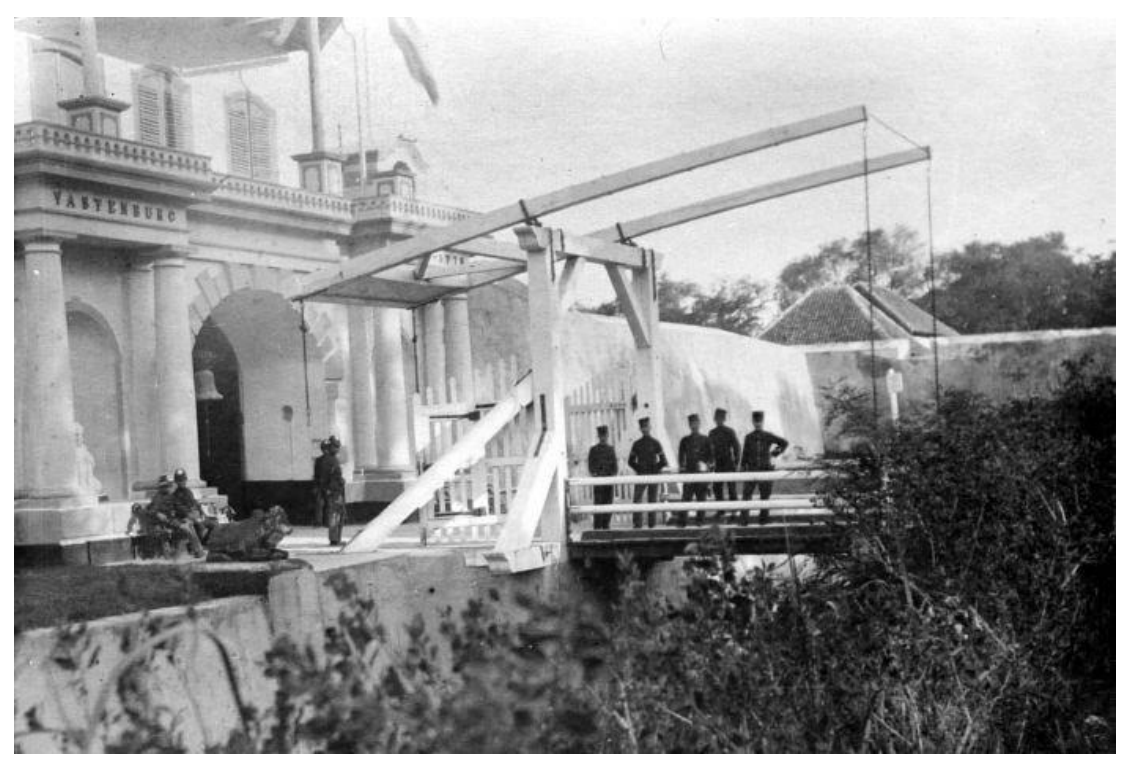

Gambar-4. Jembatan Jungkit di atas parit dan di depan pintu gerbang

Di dalam tembok benteng terdapat barak-barak yang dipergunakan untuk tempat tinggal prajurit belanda dengan keluarganya sehingga perlu dilindungi dan dijaga ekstra ketat. Untuk inilah keberadaan parit pertahanan sangat diperlukan dan berfungsi sangat vital. Sehingga eksistensi parit di Benteng Vastenburg memberi andil besar bagi peningkatan nilai sejarah benteng. 


\section{b. Melestarikan Nilai Sejarah Parit Benteng Vastenburg}

Peran parit yang sangat vital bagi benteng Vastenburg menjadikannya sebagai bagian tak terpisahkan dari keunggulan nilai sejarah benteng.

Untuk itu eksistensi parit perlu dipertahankan demi melestarikan nilai sejarahnya. Pelestariannya bisa melalui renovasi fisik bangunan dan sekaligus pengembangan fungsinya. Renovasi harus dilakukan dengan menjaga agar jangan sampai mengurangi nilai sejarahnya. Sedang perencanaan pengembangan fungsi harus disinkronkan dengan fungsi-fungsi lahan disekelilingnya.

\section{c. Kondisi Bangunan Parit Benteng Vastenburg}

Kondisi fisik bangun Parit Benteng Vastenburg saat ini secara keseluruhan sangat memprihatinkan. Talut-talutnya banyak yang pecah di beberapa titik, dasar parit ditumbuhi rerumputan dan semak, bahkan di beberapa ruas berubah fungsi menjadi tempat pembuangan sampah (Gambar-5).

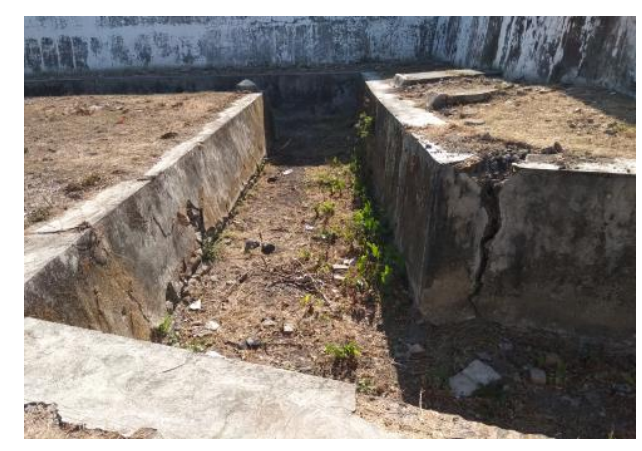

Gambar-5. Kondisi Parit Sekarang

Kondisi fisik parit yang demikian buruk ini tentunya menenggelamkan nilai sejarahnya.
Untuk itu perlu adanya usaha mengangkat citra parit menjadi salah satu obyek wisata sejarah yang menarik.

Parit benteng harus disulap menjadi obyek rekreasi baru yang lebih menyenangkan, nyaman, dan menarik. Karena parit ini pada dasarnya berfungsi untuk menampung air, maka pengembangannya harus juga tetap menjadi tempat penampungan air, namun penggunaannya untuk tujuan rekreasi, bukan untuk pertahanan keamanan.

\section{1) Desain Pengembang}

Salah satu bagian dari Benteng Vastenburg yang belum masuk dalam jajaran destinasi wisata sejarah adalah Parit. Revitalisasi parit akan bisa menyambungkan kegiatan di destinasi wisata kuliner \& belanja dengan destinasi wisata sejarah (benteng). Parit merupakan satu-satunya bagian Benteng Vastenburg yang bisa difungsikan sebagai penghubung antara destinasi wisata benteng dengan destinasi wisata sekitar (kuliner dan belanja), karena ia terletak diluar tembok benteng. Orang luar yang akan berwisata kedalam Benteng pasti melewati dulu parit benteng. Dan parit benteng ini menjadi wajah pertama yang akan dilihat orang ketika menuju ke Benteng. Oleh karena itu sangatlah relevan apabila revitalisasi dimulai dari Parit Benteng.

Karena fungsi parit sebenarnya adalah sebagai wadah badan air, maka pengembangannya harus mengarah ke pengembalian fungsi parit sebagai wadah yang menampung air. Agar air yang tertampung bisa 
dimanfaatkan terus menerus, maka harus dilakukan dalam pengembangan fungsi penampungan air ini harus bersifat permanen parit ini ialah :

(air tidak mengalir). Untuk itu langkah yang

- Merenovasi Parit menjadi kolam bersejarah namun pemanfaatannya untuk tampungan air permanen.

- Lebar Parit diperlebar menjadi $5 \mathrm{~m}$.

aktifitas wisata moderen. Pengunjungnya juga para turis kuliner dan turis belanja di sekitar

- Kedalaman parit diperdangkal menjadi Benteng. Inilah perpaduan fungsional yang $1,5 \mathrm{~m}$.

- Memfungsikan badan air di Parit untuk wisata air.

Beberapa jenis wisata air yang dapat diterapkan di Parit ini ialah:

- wisata perahu (donat boat, banana boat)

- sepeda air (angsa, ikan)

- kano

- restoran apung, pasar apung.

Desain pengembangan parit ini bisa terlihat pada Gambar 6 \& Gambar.7. Meskipun Parit harmonis dan mutualistis antara destinasi wisata sejarah Benteng Vastenburg dengan destinasi wisata sekitarnya.Dengan terpadunya destinasi wisata Benteng Vasenburg dengan destinasi wisata sekitar melalui pengembangan fungsional Parit Benteng, maka akan bisa meningkatkan apresiasi masyarakat terhadap nilai-nilai sejarah Benteng Vastenburg, sehingga akan meningkatkan minat masyarakat berkunjung ke obyek wisata sejarah yang berada di pusat kota Surakarta ini

Benteng adalah bagian dari bangunan

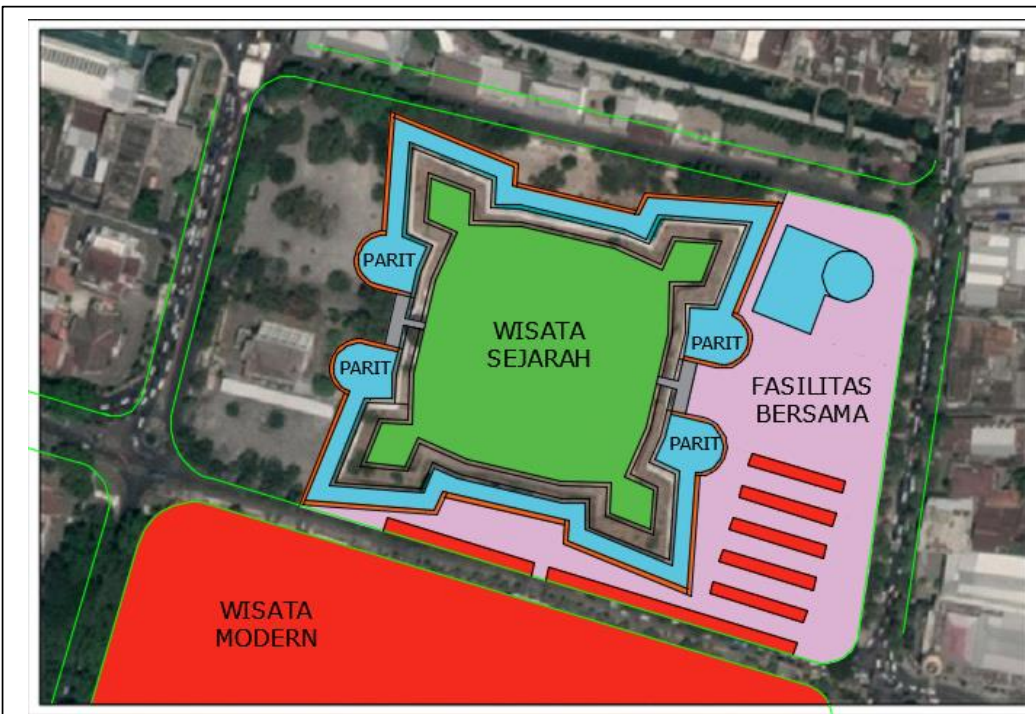

Gambar-6. Site Plan Terpadu Wisata Sejarah \& Wisata 


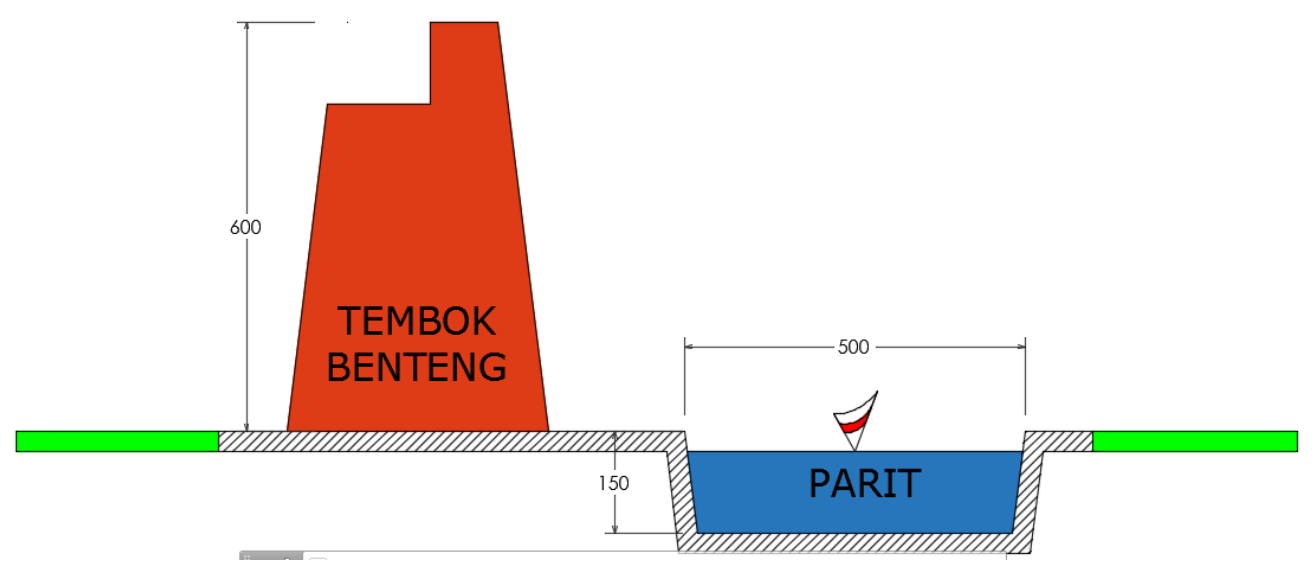

Gambar 7. Desain Parit Benteng

\section{KESIMPULAN}

1. Pengembangan fungsi Parit Benteng Vastenburg Surakarta menjadi obyek wisata air yang baru, akan dapat memadukan obyek wisata sejarah Benteng dengan obyek wisata moderen di sekitarnya.

2. Pengembangan lebih lanjut yang bisa meningkatkan sinergitas kedua jenis obyek wisata tersebut ialah dengan melengkapi obyek wisata air Parit benteng ini dengan beberapa obyek baru di lahan sekitarnya seperti taman wisata, taman kuliner, kolam renang wisata, kolam luncur, dan kolam keceh.

3. Wisata sejarah Benteng Vastenburg Surakarta bisa ditingkatkan menjadi obyek wisata kota yang lebih menarik bagi masyarakat dengan cara membuat perencanaan pengembangan wisata yang terpadu dengan obyek wisata modern di sekelilingnya.

\section{SARAN}

Untuk lebih menarik minat wisatawan terhadap obyek wisata Benteng Vastenburg, perlu dilakukan penelitian lebih lanjut terhadap bangunan tembok benteng dan ruang terbuka (open space) yang ada di dalam Benteng.

\section{DAFTAR PUSTAKA}

Suripin, Dr., Ir., M.Eng, (2004), Sistem Drainase Perkotaan Yang Berkelanjutan, Penerbit Andi Yogyakarta.

Departemen Pekerjaan Umum. 2006. UU No. 26 Tahun 2007 Tentang Penataan Ruang Kementerian Pendidikan dan Kebudayaan. 2009. UU No. 11 Tahun 2010 Tentang Cagar Budaya

Umar Kayam, (1989), Transformasi Budaya Kita, Fakultas Sastra UGM.

Pemerintah Kota Surakarta. 2015. Peraturan Daerah Kota Surakarta No. 8 Tahu 2016 Tentang Bangunan Gedung Bambang Triatmodjo, Dr., Ir., DEA, (2010), Hidrologi Terapan, Penerbit Beta Offset Yogyakarta. 
Ismadi. Ir., (2001), Prospek Pengembangan Benteng Vastenburg, Jurnal Teknik Sipil dan Arsitektur, Fakultas Teknik, Universitas

Tunas Pembangunan, Surakarta, Volume 2, no 2 Juni 2001 